\title{
Gods genade en onze vrijheid: in welke zin is genade onweerstaanbaar?
}

\author{
R.T. te Velde
}

\begin{abstract}
Since the Synod of Dordrecht (1618/19) issued its Canons, the notion of 'irresistible' grace became a hallmark of Reformed theology. Philosopher of religion Vincent Brümmer proposes to describe God's grace as a personal, not causal, relationship, with the result that it is 'rationally impossible' to reject God's grace. This article argues that Brümmer's analysis fails to sufficiently focus on the Canons' specific act of regeneration, and, using distinctions employed by 17th-century theologian William Ames, presents an understanding of 'irresistible grace' that moves beyond Brümmer's categories and includes moral, rational, and causal aspects.
\end{abstract}

\section{Inleiding}

Ruim vierhonderd jaar geleden, op 23 april 1619, werden de Dordtse Leerregels plechtig voorgelezen en vastgesteld. Sindsdien is de leer van de 'onweerstaanbare genade' een vast onderdeel van de gereformeerde geloofsleer. In de Engelse afkorting TULIP wordt de I van 'Irresistible Grace' als een van de vijf punten van het calvinisme aangevoerd. ${ }^{1}$

Het begrip 'onweerstaanbare genade' roept echter nogal wat weerstand op. Om te beginnen lijkt het duidelijk dat veel mensen - zowel in de bijbelse geschiedenis als in onze eigen tijd - wél weerstand bieden aan de roep van het evangelie, en weigeren om zich tot God te bekeren. Is dat niet voldoende bewijs dat de genade en het heilsplan van God door mensen kunnen worden tegengewerkt? Behalve dit feitelijke bezwaar is er nog een dieper ingrijpend probleem: wanneer de genade van God op onweerstaanbare wijze werkt, wordt daarmee dan de menselijke keuzevrijheid niet uitgeschakeld? Als God in het gebeuren van de wedergeboorte onze vrije wil 'overrulet', zou je dat dan niet als een daad van geweld moeten aanmerken? Forceert God ons tegen onze wil om ons tot Hem te bekeren?

1 Citaten uit de Dordtse Leerregels worden in dit artikel gegeven uit K. Zwanepol, C.H. van Campenhout (red.), Belijdenisgeschriften van de Protestantse Kerk in Nederland, Heerenveen 2009. 
Dit artikel poogt deze problematiek te verhelderen en tot een nadere omschrijving te komen van de onweerstaanbaarheid van Gods genade. Daartoe wordt in de eerste plaats aangesloten bij een hedendaagse godsdienstwijsgerige analyse door Vincent Brümmer, die een aantal mogelijke betekenissen van het begrip 'onweerstaanbaar' onderscheidt. Vervolgens worden enkele elementen naar voren gehaald uit de argumentatie die in de jaren voorafgaand aan de Dordtse synode werd ontwikkeld door de Engelse theoloog William Ames. De scholastieke onderscheidingen die Ames introduceert, helpen niet alleen om te begrijpen wat de Dordtse Leerregels verwoorden over de onweerstaanbare werkzaamheid van de Heilige Geest in het werk van de wedergeboorte, ze geven ook aanleiding om een stap verder te komen ten opzichte van de analyse van Brümmer.

\section{Wat bedoelen we met 'onweerstaanbaar'?}

Interessant genoeg is aan het vraagstuk van de 'onwederstandelijke genade' twee keer een uitgebreide discussie in Theologia Reformata gewijd. Beide keren was de Utrechtse hoogleraar godsdienstfilosofie Vincent Brümmer de initiatiefnemer voor de gedachtenwisseling. De eerste gespreksronde vond plaats in 1981, en prof. C. Graafland was toen de opponent van Brümmer. ${ }^{2}$ In 1994 gaf Graaflands opvolger als bijzonder hoogleraar vanwege de Gereformeerde Bond in Utrecht, prof. A. de Reuver, een vervolg aan het debat. ${ }^{3}$

De eerste bijdrage van Brümmer is van belang, omdat hij verschillende betekenissen van het woord 'onweerstaanbaar' onderzoekt. Het materiaal uit zijn artikel in Theologia Reformata van 1981 kwam later terecht in zijn boek Over een persoonlijk God gesproken. ${ }^{4}$ In dat boek ontwikkelt Brümmer een persoonlijk en relationeel model om de omgang tussen God en mensen te beschrijven. Een persoonlijke relatie verschilt van een causale verhouding, waarin de ene partij - God - in feite de enige handelende Persoon is die geheel bepaalt wat er met de andere partij - de mens - gebeurt. In een causale relatie wordt het handelen van mensen op strikt noodzakelijke wijze bepaald

2 V. Brümmer en C. Graafland, 'Genade en onwederstandelijkheid: I. Hoe onwederstandelijk is de genade? II. De genadeleer van Dordt. III. De genadeleer van Graafland', Theologia Reformata 24 (1981), 24-49.

3 V. Brümmer, "Deze onderscheiding aanvaard ik gaarne", Theologia Reformata 37 (1994), 242-264; A. de Reuver, “Zo'n trotse titel voor een zo geringe zaak?”, Theologia Reformata 37 (1994), 265-289; V. Brümmer, "Dat ze hem op generlei wijze kan ontroofd worden”, Theologia Reformata 37 (1994), 290-293.

4 V. Brümmer, Over een persoonlijke God gesproken: studies in de wijsgerige theologie, Kampen 1988. 
door Gods handelen, en is er dus geen echte vrijheid van menselijk handelen. Nog weer een ander model beschrijft de omgang tussen God en mensen als een zakelijke overeenkomst van rechten en plichten. In het causale model manipuleert God ons, in het zakelijke model kunnen we over onze wederzijdse belangen onderhandelen, maar in beide is er geen werkelijk persoonlijke verhouding van liefde.

Brümmer signaleert dat de meeste christelijke theologen wel over het 'onweerstaanbare' van Gods genade spreken. Maar op welke manier het dan precies 'onmogelijk' is om die genade te weerstaan, dat wordt verschillend ingevuld.

Een eerste, nogal stevige interpretatie is dat het per definitie onmogelijk is dat genade door iemand met succes weerstaan wordt. Dit noemt Brümmer de 'conceptuele' onmogelijkheid, die met het begrip 'genade' zelf gegeven zou zijn. Zijn bezwaar is, dat als we deze definitie volgen, veel van wat de Bijbel vertelt over Gods openbaring aan mensen en zijn roeping tot geloof niet als daden van genade kan gelden: velen sluiten zich immers voor Gods roepstem af. Bovendien, stelt Brümmer, is de verhouding tussen God en mens niet langer een echt persoonlijke relatie wanneer de mogelijkheid om nee tegen God te zeggen op voorhand is uitgesloten. Dan zijn we als mensen volstrekt voorgeprogrammeerd.

Gaat het dan - in de tweede plaats - om een feitelijke onmogelijkheid om ons tegen Gods genade te verzetten? Bij wijze van voorbeeld: ook al is het niet per definitie uitgesloten dat iemand ijzer met handen breekt, feitelijk zal dit nooit gebeuren gegeven de fysieke structuren van de werkelijkheid. Ook hier geldt echter - volgens Brümmer - dat we in een causale, manipulatieve verhouding met God terechtkomen als het feitelijk niet mogelijk is om tegen Gods wil in te gaan. God zou dan immers de volledige oorzaak zijn van onze daad van geloof, en wij zouden niet langer vrije, handelende personen zijn. Hiertegenover stelt Brümmer dat een echte, persoonlijke relatie tussen God en mensen symmetrisch is: beiden kunnen ja of nee zeggen. Het asymmetrische in de relatie zit in de keuze die God maakt om niet een causale, maar een persoonlijke relatie met ons te stichten.

Men zou een derde invulling van het 'onmogelijk' kunnen overwegen: het is normatief onmogelijk om genade te weerstaan. Het is verboden om tegen de genade te kiezen, en daarom kan het ook niet. Wij zijn verplicht om aan Gods goedheid ons gewonnen te geven en op de juiste manier op zijn genade te reageren. Brümmer suggereert dat juist gereformeerde theologie met deze interpretatie niet kan meegaan: dan zou immers onze daad van geloof een verdienste zijn. In een zakelijke overeenkomst van rechten en plichten levert elke partij een eigen bijdrage. 
Vanuit zijn eigen model van de persoonlijke relatie tussen God en mensen stelt Brümmer een vierde vorm van 'onweerstaanbaarheid' voor: het is onredelijk om Gods genade te verwerpen. God wil in een verhouding van liefde met ons staan. Omdat liefde wederzijds is, kan ze niet gedwongen of verdiend worden. In een liefdesrelatie is het onredelijk en daarom onmogelijk om de liefde die je van de ander krijgt af te wijzen, net zoals het onredelijk is om tegen je eigen geweten in te handelen. Door zijn onuitputtelijke liefde overtuigt, bezielt en beweegt God ons om van onze kant Hem onze liefde te betuigen. Wanneer de liefde van God ervaren wordt als onverdiende gunst, is het onmogelijk - want onredelijk - om die gunst af te wijzen.

\section{Kanttekeningen bij Brümmers voorstel}

Het verhelderende van Brümmers analyse is dat hij laat zien hoe verschillende manieren om over Gods genade te spreken geworteld zijn in verschillende modellen om de verhouding van God en mensen te beschrijven. Toch zijn er enkele bezwaren tegen het toepassen van Brümmers indeling van vier soorten 'onweerstaanbaar' op de spreekwijze van de Dordtse Leerregels.

In de eerste plaats komt het voorstel van Brümmer om het 'onweerstaanbare' uit te leggen vanuit het 'onredelijke' heel dicht bij de visie van Jacobus Arminius en zijn volgelingen in de tijd van de Dordtse synode. Met name Graafland heeft hier in zijn reactie op Brümmer in 1981 op gewezen. De remonstranten van de zeventiende eeuw vatten Gods genade vooral op als een aanbod dat wordt gedaan aan het menselijk verstand. Als mensen maar begrijpen wat God van ze wil, zal de wil vanzelf volgen. Maar die keuze van de wil blijft een vrije, op zichzelf staande daad. In principe kan de mens dus met zijn wil ervoor kiezen om het aanbod van genade af te wijzen. ${ }^{5}$ De Dordtse Leerregels verwijzen in hoofdstuk III/IV artikel 12 naar deze opvatting met de term 'aandrang op het gemoed' of 'zedelijke aanrading': er wordt een appèl op het verstand gedaan om in te zien wat goed is. Maar volgens Dordt is dat morele appèl niet afdoende: de Heilige Geest werkt rechtstreeks in op de wil van de mens, op een manier die je 'fysiek' zou kunnen noemen. De aard van de wil zelf moet veranderd worden. Genade is niet maar een aanbod: het houdt meteen ook de schenking en de deelachtigmaking van het heil in. ${ }^{6}$ Genade wordt werkelijkheid in het hart en het leven van mensen.

5 Zie over deze thematiek ook het belangrijke artikel van Aza Goudriaan, 'The Synod of Dordt on Arminian Anthropology' in: Aza Goudriaan en Fred van Lieburg (red.), Revisiting the Synod of Dordt (1618-1619), Brill's Series in Church History dl. 49, LeidenBoston 2010, 81-106.

6 Graafland, 'Genadeleer', 37. 
Het tweede bezwaar dat hiermee verbonden is, betreft het te algemene karakter van de omschrijving die Brümmer geeft van Gods genade. Hij gaat niet in op juist dat ene bijzondere gebeuren waarvan Dordt stelt dat God daarin onweerstaanbaar werkt: de bekering of wedergeboorte. Misschien zouden de gereformeerde theologen rond Dordt nog wel willen toegeven dat in veel opzichten mensen zich tegen de genade van God verzetten. Dit is zelfs de 'normale' situatie van de mensheid geworden sinds de zondeval. De toestand van mensen is een volgehouden daad van verzet. ${ }^{7}$ En nu is dit precies de vraag: hoe kan dat veranderen? Wanneer God zijn eeuwig besluit neemt om mensen van hun zonde en verderf te redden, en als Hij aan mensen zijn genade schenkt zodat zij tot inkeer en geloof komen, kan déze goddelijke genade dan weerstaan worden?

\section{Van daadkracht naar onweerstaanbaarheid}

Het is goed om erbij stil te staan dat de gereformeerden die tegen Arminius en de remonstranten ingingen, zelf niet voor het woord 'onweerstaanbaar' gekozen hebben. Ze beseften terdege dat dit woord misverstanden oproept. Het woord 'onwederstandelijk' of 'onweerstaanbaar' komt zelfs niet letterlijk in de Leerregels voor. Waar het Dordt om gaat is de daadkracht van Gods genade: genade is niets slechts een aanbod of een mogelijkheid die wordt geopend, maar Gods genade bereikt het effect dat zij beoogt. Als genade alleen een mogelijkheid aanbiedt, blijft het van de menselijke vrije wil afhangen of het er ook werkelijk van komt dat wij geloven en gered worden. Maar als die menselijke wil nu eens zó aan de zonde gebonden is, dat hij niet eens in staat is om zich van het kwaad af te keren en zich tot God te wenden? In de Dordtse Leerregels vormt de radicale onmogelijkheid van de mens om zichzelf tot het goede te bewegen de achtergrond en de keerzijde van de sterke nadruk op de werkelijke, krachtige werkzaamheid van de Geest die ons hart vernieuwt. Met andere woorden: het 'onweerstaanbare' van Gods genade kan slechts begrepen worden in de context van de leer over het heil. Daarom begint hoofdstuk

7 Vergelijk de treffende diagnose door De Reuver, “Zo'n trotse titel”, 280-281: "Wanneer Brümmer vindt dat op deze manier de menselijke verantwoordelijkheid wordt bedreigd, omdat Calvijn weigert te aanvaarden dat de mens het vermogen heeft om het ondenkbare te doen, nl. Gods aanbod afwijzen, dan zou Calvijn van dit verwijt niet van zijn stuk zijn. Hij zou repliceren dat de natuurlijke mens in het geheel niets ondenkbaars doet wanneer hij nee zegt op Gods aanzoek. Hij doet, gezien zijn slavernij, helaas veeleer iets dat volstrekt voorstelbaar is. In zijn schuldige machteloosheid kan en doet de zondaar niet anders dan nee zeggen tegen God; niet omdat hij daartoe gedetermineerd en dus tot een willoos object gereduceerd is, maar omdat hij tegen die slavernij vrijwillig ja heeft gezegd." 
III/IV met een aantal artikelen ( $1 \mathrm{t} / \mathrm{m} 5)$ waarin de radicale verdorvenheid van de in zonde gevallen mens wordt beleden. Het gaat niet maar om de algemene menselijke mogelijkheden van de wil en de vrijheid om te kiezen. Het punt in geding is wat de wil concreet en feitelijk kan of niet kan ten opzichte van God. In dat opzicht kan de bekering van de mens nooit beschreven worden als alleen maar een vrije en actieve daad van onze kant: het is ten diepste een gebeuren dat ons overkomt, waarin wij passief zijn, waarin wij genade ontvangen omdat wij onze redding niet zelf kunnen bewerken.

Het is dus beter om over de werkzame kracht van Gods genade te spreken dan over de 'onweerstaanbaarheid'. Toch geeft die laatste term wel een uiterste toespitsing aan het belijden van Gods kracht, de kracht van de Heilige Geest die levend maakt. In wat de Dordtse Leerregels uitspreken in hoofdstuk III/IV is wel degelijk verondersteld dat deze kracht op onweerstaanbare wijze werkt. Dit geldt voor de woorden in artikel 11:

Hij opent het gesloten hart, Hij vermurwt het harde en besnijdt het onbesneden hart. Hij stort in de wil nieuwe hoedanigheden en maakt dat die wil, die dood was, levend wordt, die verkeerd was, goed wordt, die onwillig was, daadwerkelijk gewillig wordt, die weerspannig was, gehoorzaam wordt.

Artikel 12 voegt daaraan toe dat deze ingreep 'in haar kracht niet minder of geringer is dan de schepping of de opwekking van de doden'.

Bovendien gaat Dordt in de Verwerping der Dwalingen bij hoofdstuk III/ IV nog iets concreter op het punt van de 'onweerstaanbaarheid' in. Dit gebeurt vooral in Verwerping nummer 8. Daar wordt als dwaling aangewezen de gedachte dat

nadat alle werkingen van de genade, die God gebruikt om de mens te bekeren, volbracht zijn, deze God en de Heilige Geest, wanneer Hij het voornemen en de wil heeft om hem wedergeboren te doen worden, toch zó kan weerstaan en metterdaad ook dikwijls weerstaat, dat hij zijn eigen wedergeboorte geheel belet; en dat het derhalve in zijn eigen macht blijft, wedergeboren te worden of niet.

Deze samenvatting toont de consequenties van wat in de Remonstrantie van 1610 was geponeerd over de aard van Gods genade: 'Maer soe vele de maniere vande werckinge derselve genade aengaet, die en is niet onwederstandelyck; want daer staet van velen geschreven, dat sy den H.Geest wederstaen hebben. Act.7 en[de] elders, op vele plaetschen.'

Wanneer de remonstranten in het grote geding over verkiezing, genade en wedergeboorte ontkennen dat de werkzaamheid van de Geest onweerstaan- 
baar is, wordt de Dordtse synode ertoe gedrongen om hiertegen stelling te nemen. In de bestrijding van deze dwaling halen de Leerregels drie bijbelteksten aan:

Dit is in strijd met de apostelen, die leren: Dat wij geloven naar de werking van de kracht van zijn sterkte (Ef. 1:19). En: Dat God het welbehagen van de goedheid en het werk van het geloof in ons met kracht vervult (1 Tess. 1:11). En: Dat zijn goddelijke kracht ons alles heeft geschonken wat voor het leven en de godzaligheid nodig is (2 Petr. 1:3).

Bij deze goddelijke kracht van de Heilige Geest kunnen we ook denken aan wat in de voorafgaande Verwerping, nummer 7, gesteld wordt met woorden uit Ezechiël 36:26: 'Ik zal $\mathrm{u}$ een nieuw hart en een nieuwe geest in u geven en zal het stenen hart uit uw vlees wegnemen en zal u een hart van vlees geven'. In al de aangehaalde schriftplaatsen wordt getuigd van een directe werking van God door zijn Geest, die zonder tussenkomst van de menselijke wil bereikt wat Hij beoogt.

\section{Behulpzame onderscheidingen door William Ames}

Intussen blijft de vraag nog wel staan: schakelt Gods genade onze vrijheid uit? Werkt God op een zó krachtdadige manier dat er van de wil en de vrijheid van mensen niets overblijft? En komen we dan toch niet in de buurt van manipulatie en geweld? In dit onderdeel geef ik enkele inzichten door die de bekende theoloog William Ames in antwoord op deze bezwaren heeft ontwikkeld. ${ }^{8}$ Ames - ook wel bekend onder de Latijnse naam Amesius - was in Engeland opgeleid als theoloog, maar vluchtte in 1610 naar Nederland. Bij de start van de Dordtse synode werd hij de persoonlijk assistent van synodevoorzitter Johannes Bogerman. Hij zat dus letterlijk dicht bij het vuur! In de jaren voorafgaand aan de synode was Ames in een langdurig debat verwikkeld met de remonstrantse predikant Nicolaas Grevinchoven uit Rotterdam. In zijn polemische geschriften bestrijdt Ames niet alleen de misvattingen van

8 Een beknopte schets van het leven van Ames en zijn betekenis voor de gereformeerde theologie wordt gegeven door W. van 't Spijker, 'Guilelmus Amesius (1576-1633)', in: T. Brienen (red.), De Nadere Reformatie en het Gereformeerd Pietisme, 's-Gravenhage 1989, 53-86. Als volwaardige biografie geldt nog steeds Keith L. Sprunger, The Learned Doctor William Ames: Dutch Backgrounds of English and American Puritanism, Urbana 1972. Voor een recente analyse van Ames als theoloog, zie Jan van Vliet, The Rise of Reformed System: The Intellectual Heritage of William Ames, Milton Keynes 2013. 
zijn opponent, maar biedt hij ook een nadere ontvouwing en verantwoording van de contraremonstrantse visie. In verband met het thema van de 'onweerstaanbare genade' haal ik met name drie elementen naar voren.

Het eerste element betreft de aard van de wedergeboorte en van het werk van de Heilige Geest daarin. In de terminologie van de vroege zeventiende eeuw kan de tegenstelling tussen de remonstrantse en de contraremonstrantse visie worden aangeduid met de woorden 'moreel' en 'fysiek' (zie ook paragraaf 3 van dit artikel). Terwijl Arminius en zijn volgelingen de bekering vooral zagen als een 'moreel' gebeuren waarin het menselijke verstand wordt aangesproken en overtuigd, betoogden de contraremonstranten dat het probleem van onze zonde niet slechts in de verblinding van ons verstand ligt, maar ook in de verkeerde gerichtheid van onze wil. Daarom is een ingreep van Gods Geest nodig die verder gaat dan het 'moreel' overtuigen van ons verstand, en die op 'fysieke' wijze de wil van de mens vernieuwt. William Ames bestrijdt de stelling van de remonstranten dat deze gereformeerde visie op het 'fysieke' karakter van de bekering van de mens - de wil zélf moet worden omgezet - alle vrijheid van de mens wegneemt. Hij maakt dan een belangrijk onderscheid tussen het 'vermogen om te weerstaan' (potentia dissentiendi vel resistendi) en de 'daad van het weerstaan' (actus dissentiendi vel resistentia ipsa). Het vermogen om te weerstaan hoeft door de genade niet te worden weggenomen, alleen de feitelijke daad van verzet gaat niet samen met het 'onweerstaanbare' werk van Gods genade. De wil met het vermogen om te kiezen behoort tot de natuur van de mens: zo zijn wij door God geschapen. In zijn verlossingswerk vernietigt God deze natuur van de mens niet. In Gods besluit om verloren mensen te verkiezen tot eeuwig behoud, blijft de menselijke natuur met het wezenlijke keuzevermogen bewaard. ${ }^{9}$ Het vermogen om te kiezen houdt in dat wij in principe ja en nee kunnen zeggen. Dit vermogen blijft volgens Ames bewaard door de wedergeboorte heen. Er is ook geen tegenstelling tussen dit keuzevermogen en de onweerstaanbare genade waarmee God reddend ingrijpt. Het enige dat niet samen kan gaan met de genadige werking van de Geest in de wedergeboorte is de feitelijke daad van verzet.

9 'Hanc autem potentiam vel dissentiendi vel resistendi non simpliciter tolli dixi per decretum praevium absolutum, aut per actionem illam gratiae, quam Deo tribuimus in hominum conversion, sed actum tantum dissentiendi, vel resistentiam ipsam.' William Ames, Rescriptio scholastic et brevis ad Nicolai Grevinchovii responsum illud prolixum, quod opposuit dissertationi, de redemptione generali, et electione ex fide praevisa, Amsterdam 1615, 143. 
Anders krijgen we namelijk een directe tegenstrijdigheid tussen 'wedergeboren worden' (van Gods kant, door zijn genade) en 'niet wedergeboren worden' (van onze kant, door onze blokkade).

Achter deze onderscheiding die Ames voorstelt, liggen nog andere logische onderscheidingen die in de gereformeerd-scholastieke theologie algemeen aanvaard waren. ${ }^{10}$ De belangrijkste is het onderscheid tussen de 'gedeelde zin' (sensus divisus) en de 'samengestelde zin' (sensus compositus) waarin een bepaalde uitspraak kan worden geanalyseerd. Het standaardvoorbeeld uit de middeleeuwse logica is: 'Socrates zit en loopt'. Deze uitspraak is onwaar wanneer zij in samengestelde zin wordt opgevat: dan zou Socrates tegelijk moeten zitten en lopen, en dat is onmogelijk. De uitspraak kan echter ook anders worden opgevat, namelijk in twee delen: 'Socrates zit' en 'Socrates loopt'. Beide kunnen waar zijn, alleen niet op hetzelfde moment. Maar op het moment dat Socrates zit (t1) is het logisch gezien mogelijk dat hij loopt (t2). Geen van beide - het zitten of het lopen - is in zichzelf een noodzakelijke stand van zaken; daarom is de tegenovergestelde optie eveneens mogelijk. Dat deze twee acties zich op verschillende tijdsmomenten kunnen voordoen (diachroon) betekent ook, dat op hetzelfde moment beide mogelijk zijn (synchroon), ook al is slechts één van de opties gerealiseerd. Een ander woordpaar dat ditzelfde logische inzicht uitdrukt is het onderscheid tussen 'de gelijktijdige mogelijkheid' (simultas potentiae) en de 'mogelijke gelijktijdigheid' (potentia simultatis). Dat Socrates zit en loopt is wel 'tegelijk mogelijk', maar het is niet 'mogelijk tegelijkertijd'.

Toegepast op de verhouding van goddelijke genade en menselijke vrijheid in het proces van de bekering of wedergeboorte, kunnen we stellen dat het vermogen om te weerstaan door de krachtdadige genade wordt weggenomen in de samengestelde zin, maar niet in de gedeelde zin. Zoals Ames uitlegt:

Dit is wat de onderscheiding betekent: als de [menselijke] wil door de genade bepaald wordt, en daadwerkelijk en onfeilbaar ertoe bewogen wordt om in te stemmen, dan heeft hij weliswaar niet de mogelijkheid om gelijktijdig te weerstaan [in samengestelde zin], maar wel het gelijktijdige vermogen [in gedeelde

10 Een belangrijk hulpmiddel bij de interpretatie van teksten uit de gereformeerd-scholastieke theologie is Richard A. Muller, Dictionary of Latin and Greek Theological Terms: Drawn Principally from Protestant Scholastic Theology, 2e druk, Grand Rapids 2017. De in dit artikel besproken onderscheidingen worden breder uitgelegd en toegepast in Willem J. van Asselt, J. Martin Bac en Roelf T. te Velde (red.), Reformed Thought on Freedom: The Concept of Free Choice in the History of Early-Modern Reformed Theology, Texts and Studies in Reformation and Post-Reformation Thought, Grand Rapids 2010. 
zin] om te weerstaan, zij het ook niet op een gelijkwaardige of volstrekt onverschillige wijze. ${ }^{11}$

Wat Ames in het laatste deel van dit citaat afwijst, is de visie die aan het begin van de zeventiende eeuw vooral door jezuïeten in de Rooms-Katholieke Kerk werd verdedigd. De bestrijding van deze opvatting is het tweede element uit Ames' polemiek dat voor ons thema van belang is. Kern van de afgewezen visie is het woord 'onverschillig' oftewel 'indifferent'. ${ }^{12}$ De theologen die Ames op de korrel neemt, stelden dat ook als voorzien is in alles wat voor het maken van een bepaalde keuze nodig is, de menselijke wil zich nog altijd neutraal of onverschillig opstelt, en precies de andere kant op kan kiezen. De koppeling tussen bijvoorbeeld het morele oordeel dat iets goed is en de beslissing om al of niet dat goede te kiezen wordt daarmee losgemaakt. Ik kan ervan overtuigd zijn dat het de best mogelijke handeling in een bepaalde situatie is om een oud vrouwtje te helpen oversteken, en desondanks botweg doorlopen. Ook het voorzienige bestuur en het raadsbesluit van God zijn volgens de jezuïeten rond 1600 geen voldoende voorwaarde om de door God gewilde gebeurtenis tot stand te brengen: de menselijke wil is nog altijd onverschillig, als een soort koorddanser die balanceert tussen twee uitersten. Toegepast op het proces van de bekering: zelfs wanneer God alles doet om een mens tot bekering te brengen, kan die persoon nog onbeslist blijven op het punt van zich aan Gods genade gewonnen te geven of die te weerstaan, en met die onverschilligheid wordt dan Gods daad van bekering tenietgedaan. Volgens Ames is die combinatie ondenkbaar. In het werk van wedergeboorte en bekering blijft het fundamentele vermogen van de mens om ja of nee te zeggen wel bewaard, maar dit vermogen kan niet op het eigen moment van de bekering een nee produceren.

Ames maakt nog een volgende, hier als derde genoteerde onderscheiding die van belang is om iets te begrijpen van hoe Gods genade en menselijke vrijheid samengaan. Daarbij zet hij de accenten weer net anders dan in het eerdere deel van zijn betoog. Behalve tussen het keuzevermogen op zich (potentia resistendi) en de concrete daad van het kiezen voor of tegen God (actus

11 "Distinctionis hujus haec mens est; quum determinatur voluntas per gratiam, et efficaciter movetur atque infallibiliter ad assentiendum; quamvis non habeat potestatem simul dissentiendi, simul tamen habet potestatem dissentiendi licet non omni modo aequalem, aut absolute indifferentem." Ames, Rescriptio, 151.

12 Een uitgebreide weerlegging van deze zelfde theorie door de bekende Geneefse theoloog Francesco Turrettini is te vinden in hoofdstuk 6 'Beyond Indifference: An Elenctic Locus on Free Choice by Francesco Turrettini (1623-1687)', van Van Asselt e.a. (red.), Reformed Thought on Freedom, 171-200. 
resistendi), kun je namelijk ook onderscheid maken tussen de principiële gerichtheid van onze wil (Ames noemt die in dit verband de 'eerste act', actus primus) en de concrete daden waarin die gerichtheid zich uit (in Ames' terminologie de 'tweede act', actus secundus). Juist die principiële gerichtheid staat sinds de zondeval altijd verkeerd, van God af en tegen God in. Wat er gebeurt als Gods genade ingrijpt in ons hart, is dat de richting van onze wil wordt omgekeerd. Op dat moment doen we zelf even niet mee. Zoals de Dordtse Leerregels het formuleren, is dit wat God 'zonder ons in ons tot stand brengt' (III/IV,12). Op dit niveau werkt genade onweerstaanbaar, want anders zouden wij in onze weerstand blijven hangen, en komt er nooit een verandering in onze wil. Maar Ames stelt dat in de concrete daden waarin deze 'omgezette' wil zich uit, wel degelijk weer vrijheid bestaat:

Deze ingestorte genade bepaalt strikt genomen de wil alleen in de 'eerste act', op zo'n manier dat er een zekere vrijheid blijft ten opzichte van de 'tweede act'. Deze [tweede act] volgt weliswaar onfeilbaar op de kracht die haar beweegt, maar niet elke vrijheid of mogelijkheid tot het tegengestelde wordt erdoor opgeheven. ${ }^{13}$

Dezelfde gedachte wordt ook in de Dordtse Leerregels uitgesproken: 'Wanneer de wil vernieuwd is, wordt hij niet alleen door God geleid en bewogen; maar door God in beweging gebracht, werkt hij ook zelf. Daarom wordt terecht gezegd dat de mens zelf gelooft en zich bekeert door de genade, die hij ontvangen heeft.' Een opvallende zegswijze, die we in de gereformeerde traditie ook soms weer vergeten zijn. De mens gelooft zélf en bekeert zich zélf. Daarin zijn ook weer keuzes te maken, tussen de verschillende (goede) daden die binnen ons bereik liggen. Maar dat kan alleen door de genade die ons hart en onze wil fundamenteel nieuw maakt.

\section{Terugblik en conclusie}

Schakelt Gods genade de menselijke vrijheid uit? Wat bedoelen we als we spreken over 'onweerstaanbare genade'? Op dit punt kunnen wij leren van William Ames. In zijn discussie met de remonstrant Grevinchoven hield Ames als gereformeerd theoloog vast aan belangrijke aspecten van de menselijke vrijheid, juist rond het ingrijpende gebeuren van de wedergeboorte. Het

13 'Gratia illa infusa non determinat voluntatem proprie nisi in actu primo ita ut libertas quaedam remaneat ad actum secundum : qui licet infallibiliter sequitur motionis efficacis vi, libertatem omnem tamen aut potentiam ad contrarium non tollit.' Ames, Rescriptio, 150-51. 
is eenvoudigweg niet waar dat gereformeerden in het spoor van Dordt alleen weet hebben van een allesbepalend principe van uitverkiezing dat aan de menselijke wil geen ruimte laat. William Ames houdt er - evenals de Dordtse Leerregels - aan vast dat het keuzevermogen om ja of nee te zeggen zozeer bij de mens hoort, dat dit vermogen ook in de wedergeboorte blijft bestaan. Maar het wordt wel fundamenteel van richting veranderd. Sinds de zondeval kan er uit onze eigen keuzes niets goeds voortkomen. De vrije wil brengt ons nooit bij God terug. Die wil moet eerst veranderd worden, omgebogen in de goede richting. Op dat punt zijn wij passief en werkt Gods Geest op onweerstaanbare wijze. Anders zouden de genade en de verkiezing tevergeefs zijn. In zijn discussie met Brümmer in 1994 ging De Reuver in op de vraag: wat doet de vrije wil? Hij sluit dan aan bij de middeleeuwse denker Bernard van Clairvaux, die de prachtige paradox formuleerde: 'Wat doet de vrije keuze? Zij wordt gered.'14 Daar zit precies het wonder van de wedergeboorte in. Wij dragen daar zelf niet aan bij. Wij wórden opnieuw geboren.

Ten slotte keren we terug naar de indeling van betekenisaspecten die Vincent Brümmer aanwees als mogelijke interpretaties van het woord 'onweerstaanbaar'. Volgens Brümmer is het onredelijk om Gods genade te verwerpen. Welke rationeel functionerende persoon kan zo'n overstelpende en onverdiende gunst van zich afhouden? Toch houden de Dordtse Leerregels overeind dat dit volgens de Schrift precies de natuurlijke reactie van mensen is sinds de zondeval. Het is volmaakt 'redelijk' voor ons om ons van God af te keren, dat is nu juist de keuze waarin wij mensen onszelf sinds die eerste kwade dag hebben vastgezet. De enige manier om daarvan los te komen is dat die natuurlijke gerichtheid van onze wil wordt veranderd. Alleen dan kunnen wij tot geloof en bekering komen. Gods genade doet niet alleen een moreel appèl op ons, dat wij in alle redelijkheid niet kunnen weigeren. God brengt met zijn genade werkelijk iets in ons tot stand, op causale of fysieke wijze, omdat wij het zelf niet kunnen. Dat Gods genade in een causale zin onweerstaanbaar is, kunnen we specificeren door onderscheid te maken tussen het principiële vermogen van onze wil om te kiezen (en dus ook om nee te zeggen) en de concrete daad van verzet of weerstand. In het werk van wedergeboorte en bekering blijft het fundamentele vermogen van de mens om ja of nee te zeggen bewaard, maar dit vermogen kan niet op het eigen moment van de bekering een nee produceren. Op dat punt is de daad van Gods genade waarmee Hij ons hart vernieuwt van een zodanige kracht, dat wij ons niet langer kunnen verzetten. Is dat goddelijk geweld tegen onze wil? Nee, het is de enige weg

14 De Reuver, 'Zo'n trotse titel', 266. 
tot behoud. 'Want uit genade bent u zalig geworden, door het geloof, en dat niet uit $\mathrm{u}$, het is de gave van God; niet uit werken, opdat niemand zou roemen' (Ef. 2:8-9).

R.T. te Velde is universitair hoofddocent systematische theologie aan de Theologische Universiteit Kampen en hoofddocent historische theologie aan de Evangelische Theologische Faculteit Leuven. 